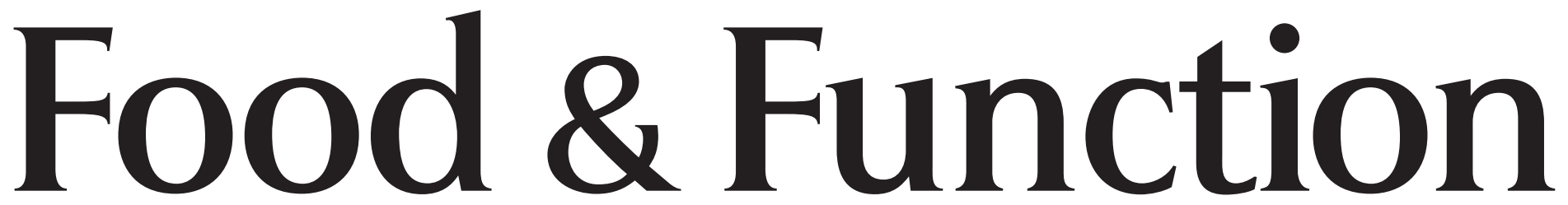

Linking the chemistry and physics of food with health and nutrition

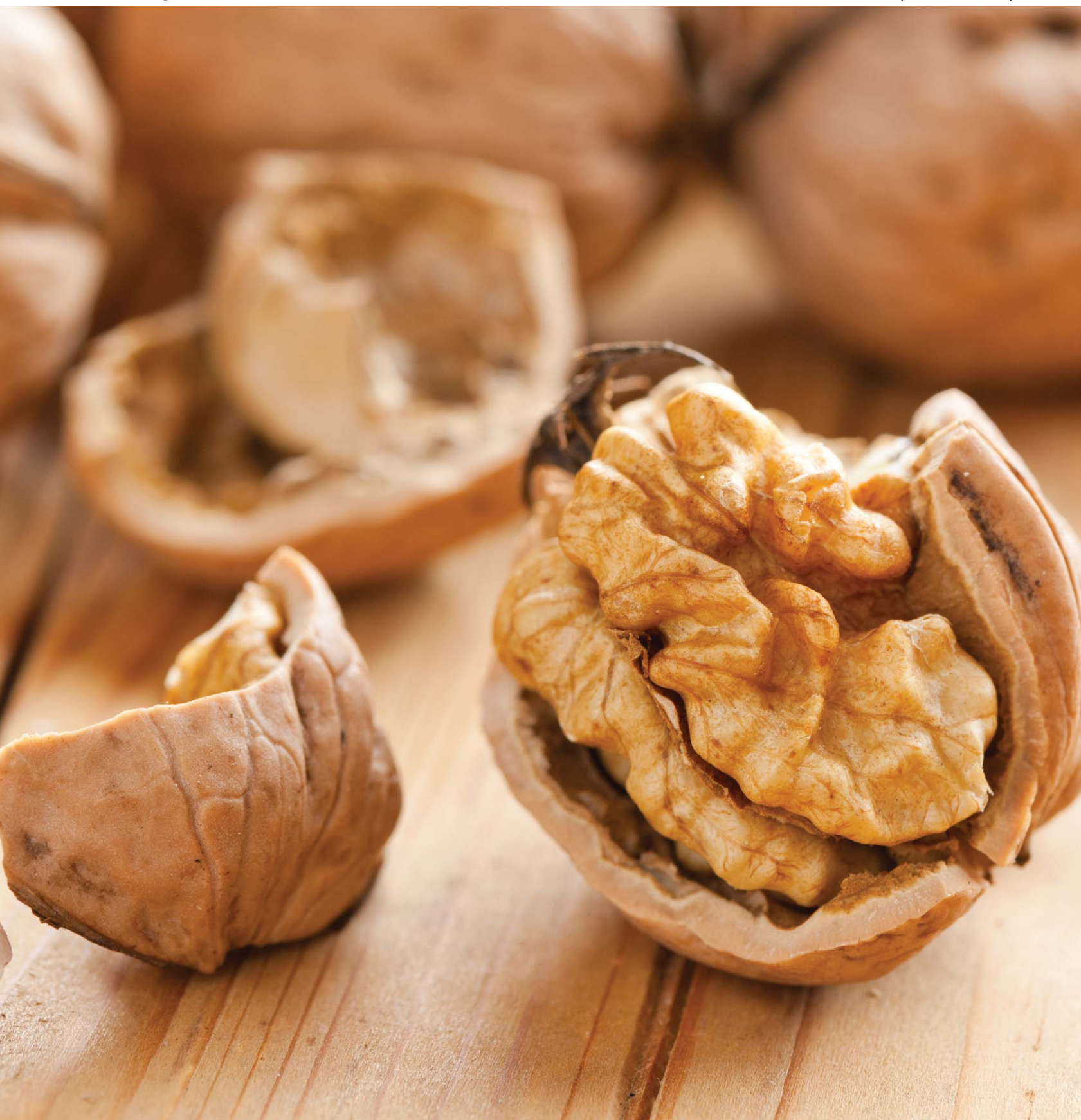




\title{
Nuts, especially walnuts, have both antioxidant quantity and efficacy and exhibit significant potential health benefits
}

\author{
Joe A. Vinson* and Yuxing Cai \\ Received 18th November 2011, Accepted 21st November 2011 \\ DOI: 10.1039/c2fo10152a
}

\begin{abstract}
Free and total (after basic hydrolysis) polyphenols in nine types of raw and roasted nuts and two types of peanut butter (54 commercial samples) were analyzed after methanol extraction by a single step Folin-Ciocalteu reagent using catechin as standard. Walnuts had the highest free and total polyphenols in both the combined raw and roasted samples. Total polyphenols in the nuts were significantly higher than free polyphenols. Roasting had little effect on either free or total polyphenols in nuts. Raw and roasted walnuts had the highest total polyphenols. The efficacy of raw and roasted nut antioxidants was assessed by measuring the ability of the free polyphenol nut extracts to inhibit the oxidation of lower density lipoproteins (LDL + VLDL). A nut polyphenol, catechin, was measured after binding of three nut extracts to lower density lipoproteins. Walnut polyphenols had the best efficacy among the nuts and also the highest lipoprotein-bound antioxidant activity. Based on USDA availability data, the per capita total polyphenols was $162 \mathrm{mg}$ from nuts per day in 2008 . This corresponds to $19 \%$ of the total polyphenols from fruits and vegetables, nuts, grains, oils and spices in the US diet. Nuts provided 158 $\mathrm{mg}$ of polyphenols per day to the European Union diet. Nuts are high in polyphenol antioxidants which by binding to lipoproteins would inhibit oxidative processes that lead to atherosclerosis in vivo. In human supplementation studies nuts have been shown to improve the lipid profile, increase endothelial function and reduce inflammation, all without causing weight gain. These qualities make nuts

a nutritious healthy snack and food additive.
\end{abstract}

\section{Introduction}

Since nuts have favorable fatty acid and nutrient profiles, there is growing interest in evaluating their role in a healthy diet. While fat accounts for $50-75 \%$ of the weight of the nuts, the amount of saturated fatty acids is quite low ranging from $4-15 \%$. Among the nuts, walnuts have the highest weight $\%$ of PUFA and also the highest $\% 18: 2(\mathrm{n}-6)$, and the highest $\% 18: 3(\mathrm{n}-3), 47,38$, and $9 \%$, respectively. ${ }^{1}$ When consuming the high-energy dense nuts, there is a satiety effect and low metabolizable energy. In addition, nut consumption increases elevated resting energy expenditure and elicits a thermogenic effect of feeding. ${ }^{2}$ These mechanisms provide the rationale for the fact that clinical studies show that nuts are not associated with weight gain., ${ }^{3,4}$ In fact in a Spanish study those who ate nuts twice a week were $31 \%$ less likely to gain weight than those who did not eat any nuts. ${ }^{5}$

Nut consumption also has a favorable effect on the lipid profile and cardiovascular disease risk factors as demonstrated by numerous supplementation studies involving almonds, hazelnuts, Macademia, peanuts, pistachios, walnuts, and mixed

Department of Chemistry, University of Scranton, Scranton, PA, 18510 USA. E-mail: vinson@scranton.edu; Fax: +1-570-941-7510; Tel: +1-570-941-7551 nuts. ${ }^{6-20}$ The lipid effect was examined in subjects with normal and with high cholesterol. Interestingly the cholesterol-lowering effect of the nuts as shown by supplementation is greater than that predicted based on the amount and nature of fat consumed. ${ }^{21}$ These results suggest that there are other bioactive constituents present in the nuts besides the fats. We hypothesize that these compounds are polyphenols. This hypothesis is strengthened by the human supplementation studies. Almonds, cashews, peanuts and walnuts have been shown to increase plasma antioxidant capacity and/or plasma oxidized LDL and oxidative stress. ${ }^{12,22-27}$ Nuts and oxidation has been recently reviewed. ${ }^{28}$

Plant polyphenols include simple phenolic acids, flavonoids, stilbenes and a variety of other polyphenolic plasma antioxidant capacity and/or decrease plasma oxidized compounds which possess hydroxy groups bound to an aromatic group. Flavonoid content of nuts has been measured by HPLC from four regions of the US by the Nutrient Data Laboratory of the USDA. ${ }^{29}$ Twenty compounds were analyzed and the highest total flavonoids were found in pecans ( $9.5 \mathrm{mg}$ per $28 \mathrm{~g}$ serving size) with almonds second at $4.2 \mathrm{mg}$. No flavonoids were detected in Brazil or Macademia nuts. Proanthocyanidins, large molecules not bioavailable to humans, are present in very high amounts in nuts, ranging from $140 \mathrm{mg}$ in hazelnuts and pecans to $3 \mathrm{mg}$ in cashews. 
Total polyphenols as measured by ox-redox reactions are best done after hydrolysis to liberate any polyphenols bound as esters or ethers primarily to the polysaccharide matrix (fiber) which is high in nuts ranging from $5.9 \%$ in cashews to $10.4 \%$ in hazelnuts. ${ }^{1}$ We measured free and total polyphenols in both fresh and roasted nuts. In addition we measured the efficacy of the antioxidants in the nuts and determined whether the polyphenols in the nuts bind to lower density lipoproteins and protected the lipoproteins from oxidation. Using per capita consumption data we also calculated the contribution of nuts to the daily antioxidants in the US diet.

\section{Materials and methods}

Nine types of nuts $(n=50)$ and peanut butter $(n=4)$ were purchased from local supermarkets and from the internet. The samples were refrigerated before analysis. Nut samples were ground in a mortar and pestle under liquid nitrogen and stored at 4 ${ }^{\circ} \mathrm{C}$ prior to assay. Fat and the fat-soluble vitamins in one gram samples were removed by two extractions with $5 \mathrm{ml}$ of hexane. After pouring out the liquid the residual hexane in the nuts was evaporated with nitrogen. A $100 \mathrm{mg}$ sample of hexane-treated ground nuts (in duplicate) was put into a $10 \mathrm{ml}$ screw-capped plastic tubes and shaken with $10 \mathrm{ml}$ of methanol for $48 \mathrm{~h}$ at room temperature. The extracts were quantitatively transferred to a 10 $\mathrm{ml}$ volumetric flask and then diluted to volume with methanol. This is the sample extract for measurement of free polyphenols. Hydrolysis was carried out by adding $100 \mathrm{mg}$ of defatted ground nuts (in duplicate) to $5 \mathrm{ml}$ of $1.2 \mathrm{M} \mathrm{NaOH}$ in methanol in a screwcapped tube and shaken for $3 \mathrm{~h}$ at $37^{\circ} \mathrm{C}$. The extract was diluted to $10 \mathrm{ml}$ in a volumetric flask. This is the extract for the assay of total polyphenols. Extracts were stored at $-80{ }^{\circ} \mathrm{C}$ until assayed.

\section{Polyphenol assay}

Kinetic studies were done in order to determine the optimum time for extraction and also for hydrolysis. For extraction, cashews were shaken with methanol at room temperature and aliquots removed at 24, 48 and $72 \mathrm{~h}$ prior to Folin assay. Maximum extraction occurred at $48 \mathrm{~h}$. For hydrolysis, almonds were shaken with $\mathrm{NaOH}$ in methanol at $37{ }^{\circ} \mathrm{C}$ and aliquots removed every $30 \mathrm{~min}$ for $5 \mathrm{~h}$. Three hours were needed for maximal extraction and hydrolysis. We measured the amount of interferences in the water eluates from the Polyclar columns from the free and total polyphenol extracts. The amount of interferences ranged from 0 to $3 \%$ of the Folin values among all the nut samples.

Polyphenols were measured in the extracts using the FolinCiocalteu reagent (Sigma Chemical Co.) diluted 1:9 with nanopure water (Millipore Q). Catechin hydrate (Sigma) was used at 5 to $50 \mu \mathrm{M}$ in the cuvette and measurements were made after $30 \mathrm{~min}$ at $750 \mathrm{~nm}$ vs. a reagent blank with $100 \mu \mathrm{L}$ of methanol to generate the standard curve. Due to possible interferences present in the nut extracts which may give a positive response with the Folin reagent, we used a new solid phase method to adsorb polyphenols, and the eluate contained watersoluble interferences. Polyvinylpyrrolidone (Polyclar VT, GAF Chemicals, Wayne, NJ) was used as the solid phase and $0.38 \mathrm{~g}$ of the powder was added to a $10 \mathrm{ml}$ syringe with $0.1 \mathrm{~g}$ of cotton used as a bed. The Polyclar column was prepared by washing with $5 \mathrm{ml}$ of methanol, followed with $5 \mathrm{ml}$ of $0.012 \mathrm{M} \mathrm{HCl}$. One $\mathrm{ml}$ of nut extracts (free and total) were each diluted to $10 \mathrm{ml}$ after $4 \mathrm{M} \mathrm{HCl}$ addition to acidify the solution to $\mathrm{pH} \mathrm{2-4.} 4 \mathrm{ml}$ of diluted nut extract was pipetted on the column and $4 \mathrm{ml}$ of water used to wash the column. The eluants were combined and diluted to $10 \mathrm{ml}$ with water and the solid phase discarded. The Folin assay was then done using a larger volume of extract due to the dilution. For the Folin assay sugars are often listed as interferences with the standard two step method of Singleton. ${ }^{30}$ Our single step Folin method showed no positive interferences with $1 \mathrm{mM}$ glucose and fructose.

\section{Antioxidant efficacy}

The efficacy of antioxidants in the hydrolyzed and neutralized nut extracts was examined using our standard published in vitro "heart disease in a test tube" model in which lower density lipoprotein (LDL + VLDL) is isolated from the plasma of a normocholesterolemic subject after approval was obtained from the Institutional Review Board. Lipoproteins were subjected to oxidation with or without added antioxidants added at different concentrations. ${ }^{31}$ Oxidation is at physiological $\mathrm{pH}$ (7.4) and temperature $\left(37^{\circ} \mathrm{C}\right)$ and is initiated by addition of cupric ion (final concentration $25 \mu \mathrm{M}$ ) and oxidation is continued for $6 \mathrm{~h}$. Lipid oxidation is measured by fluorometry in a control with no added antioxidants and in the samples with thiobarbituric acid reagent from Sigma. The concentration to inhibit the oxidation by $50 \%\left(\mathrm{IC}_{50}\right)$ is determined as the measure of the efficacy of the antioxidants. One raw and one roasted nut of each type was measured in duplicate. Phenol antioxidant index (PAOXI) is a combined measure of both quantity and efficacy of the antioxidants present. It is calculated by dividing the quantity of polyphenols in raw nuts and peanut butter in $\mu \mathrm{m} \mathrm{kg}^{-1}$ units by the $\mathrm{IC}_{50}$ in uM units. ${ }^{32}$

\section{Lipoprotein binding and antioxidant activity}

A standard method was used ${ }^{31}$ for determination of binding and lipoprotein-bound antioxidant activity. LDL + VLDL isolated in $2.7 \% \mathrm{NaCl}$ was diluted to $0.7 \% \mathrm{NaCl}$ to mimic physiological conditions. $4 \mathrm{ml}$ was used for the spiking experiments. Methanol, pure catechin, gallic acid and $\alpha$-tocopherol (Sigma) in methanol and three unhydrolyzed and neutralized nut extracts were added separately at 1 and $5 \mu \mathrm{M}$ polyphenol concentrations (Folin) to the LDL + VLDL and allowed to equilibrate at $37^{\circ} \mathrm{C}$ for $2 \mathrm{~h}$, before $2.5 \mathrm{ml}$ was then put through a heparin-agarose (Sigma) lipoprotein affinity column and free polyphenol eluted with $0.7 \%$ $\mathrm{NaCl}$. Polyphenol-bound LDL + VLDL was isolated by elution with $2.5 \% \mathrm{NaCl}$. After analysis of protein this latter eluate was then subjected to oxidation with cupric ion at $37^{\circ} \mathrm{C}$ after dilution with PBS to a protein concentration of $70 \mu \mathrm{g} \mathrm{ml}^{-1}$, and the formation of conjugated dienes measured at $234 \mathrm{~nm}$. Lag time was determined for the blank and samples. The concentration of pure polyphenols and catechin in the bound polyphenol sample was measured by HPLC using a C18 column and methanol/ phosphoric acid 96:10 adjusted to $\mathrm{pH} 2.5$ with potassium dihydrogen phosphate. Electrochemical detection at the optimum voltage was done by the ESA Coularray detector. 


\section{Per capita calculations}

Per capita nut and other food consumption data was obtained from the USDA database using the most recent data from $2008 .^{33}$ It was combined with our total polyphenol assay (average of raw and roasted) to estimate the per capita consumption of nuts in comparison to our fruits and vegetables estimates updated to 2008. ${ }^{34,35}$ For the European Union (EU), a 2007 market information database was used. ${ }^{36}$

\section{Results}

\section{Quantity of antioxidants}

Results of free and total polyphenols for all the nut samples are displayed in Table 1. Walnuts were significantly higher in free and total polyphenols with raw and roasted data combined than all the other nuts $(p<0.002)$. Total polyphenols in nuts were significantly higher than free polyphenols for all nuts combined $(p<0.00001)$. The order for total polyphenols in raw nuts is the following: walnut $>$ Brazil $\gg$ pistachio $\sim$ pecan $\sim$ peanut $\sim$ almond $\gg$ Macademia $\gg$ cashew $\sim$ hazelnut. The order of total polyphenols in roasted nuts is the following: walnut $\gg$ Brazil $\gg$ hazelnut $>$ peanut $\sim$ pecan $\sim$ cashew $>$ Macademia $\sim$ almond $>$ pistachio. Total polyphenols in peanut butter were similar in the creamy and crunchy varieties and considerably lower than roasted Peanuts but the difference was not significant. Statistically total polyphenols for roasted walnut were higher than almond $(p<0.01)$ and Brazil was higher than almond $(p<$ $0.05)$. Except for Brazil, walnut total polyphenols were significantly higher than all the other nuts $(p<0.02)$. There was no significant difference between free polyphenols in raw and roasted nuts. Total polyphenols were slightly higher in roasted than raw nuts. The \% free polyphenols in the nuts and peanut butters ranged from $18.9 \%$ in roasted cashews to $90.0 \%$ in roasted hazelnuts. There was no significant difference between $\%$ free in raw and roasted nuts.

\section{Antioxidant efficacy}

The antioxidant efficacy of the different nuts is shown by the $\mathrm{IC}_{50}$ value in Fig. 1. The order of decreasing efficacy (increasing $\mathrm{IC}_{50}$ ) for raw nuts is walnut $>$ cashew $>$ hazelnut $\sim$ pecan $\sim$ almond $\sim$ Macademia $>$ pistachio $>$ Brazil $>$ peanut. For roasted nuts and

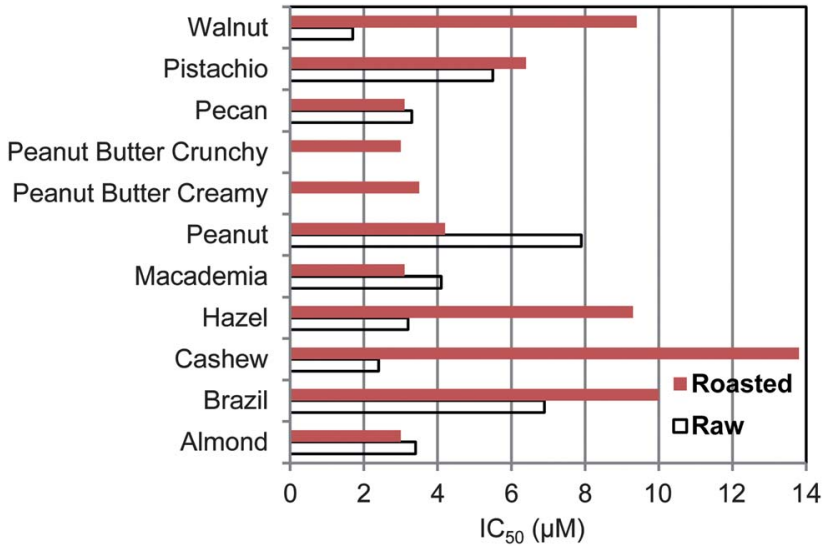

Fig. 1 Antioxidant efficacy of nut and peanut butter polyphenols as measured by the concentration to inhibit the oxidation of LDL + VLDL by $50 \%$ compared to control with no added antioxidants.

peanut butters the order is almond $\sim$ Macademia $\sim$ pecan $\sim$ peanut butter crunchy $>$ peanut butter creamy $>$ peanut $>$ pistachio $>$ hazelnut $\sim$ walnut $>$ Brazil $>$ cashew. Roasting causes a decline in efficacy; the average $\mathrm{IC}_{50}$ for raw nuts is $4.3 \pm$ $2.1 \mu \mathrm{M}$ and for roasted nuts (not including Peanut Butters) is 6.9 $\pm 3.9 \mu \mathrm{M}$. This is a $37 \%$ decrease but it is not quite significant, $p=0.14$. In addition to the nuts, tocopherol and gallic acid which are both present in nuts, were tested and their $\mathrm{IC}_{50}$ values were 25.8 and $3.5 \mu \mathrm{M}$, respectively. Thus nuts on average had over 3 times better antioxidant efficacy than $\alpha$-tocopherol, ranging from 15 times for raw walnut to 1.9 times for roasted cashew, the poorest antioxidant among the nuts. Raw walnut had the highest antioxidant efficacy among all the nuts. The phenol antioxidant index (PAOXI), a combined measure of quantity and efficacy, was highest for pecan and closely followed by walnut. Nuts average 11100 which was higher than 23 vegetables, $9170,{ }^{35}$ and lower than 20 fruits, $27400 .^{34}$

\section{Lipoprotein binding}

Results for the binding experiment are shown in Table 2. Catechin was found in all three of the unhydrolyzed nut samples and it was analyzed in the bound LDL + VLDL fraction. There is a dose-response effect for binding of nut polyphenols indicating

Table 1 Free and total polyphenols in nuts and peanut butter ( $\mu$ mol catechin equivalents/g)

\begin{tabular}{|c|c|c|c|c|}
\hline Nut & \multicolumn{2}{|l|}{ Raw } & \multicolumn{2}{|l|}{ Roasted } \\
\hline Brazil $(\mathrm{n}=4)$ & $33.7 \pm 0.0(33.7)$ & $66.1 \pm 8.8(59.8$ to 72.3$)$ & $17.0 \pm 0.8(16.4$ to 17.6$)$ & $73.2 \pm 8.5(67.2$ to 79.2$)$ \\
\hline Cashew $(\mathrm{n}=7)$ & $21.0 \pm 1.6(17.9$ to 22.8$)$ & $28.6 \pm 2.3(25.9$ to 30.2$)$ & $19.3 \pm 2.5(17.9$ to 22.1$)$ & $49.3 \pm 24.0(26.4$ to 71.6$)$ \\
\hline Hazelnut $(\mathrm{n}=4)$ & $21.6 \pm 0.6(21.2$ to 22.0$)$ & $26.7 \pm 2.0(25.3$ to 28.1$)$ & $22.6 \pm 0.6(20.4$ to 23.1$)$ & $61.4 \pm 43.6(38.5$ to 100$)$ \\
\hline Macademia $(n=4)$ & $15.0 \pm 2.9(12.9$ to 17.0$)$ & $39.1 \pm 10.1$ (31.9 to 46.2$)$ & $11.1 \pm 4.2(8.1$ to 14.0$)$ & $45.1 \pm 23.2(28.6$ to 61.5$)$ \\
\hline Peanut Butter (Crunchy $(\mathrm{n}=2)$ & N/A & N/A & $16.0 \pm 0.8(14.5$ to 15.4$)$ & $32.5 \pm 1.8(31.2$ to 33.8$)$ \\
\hline Pecan $(n=4)$ & $22.3 \pm 3.4(19.9$ to 24.7$)$ & $49.9 \pm 23.1(33.5$ to 66.2$)$ & $16.6 \pm 0.6(16.2$ to 17.0$)$ & $50.0 \pm 17.9(37.4$ to 62.7$)$ \\
\hline Pistachio $(\mathrm{n}=6)$ & $15.8 \pm 1.7(14.6$ to 17.0$)$ & $51.9 \pm 0.4(51.6$ to 52.1$)$ & $19.9 \pm 3.7(15.4$ to 20.8$)$ & $39.7 \pm 24.5(25.3$ to 76.1$)$ \\
\hline Walnut $(\mathrm{n}=4)$ & $31.9 \pm 6.9(27.0$ to 36.8$)$ & $69.3 \pm 16.5(57.6$ to 81.0$)$ & $65.5 \pm 9.1(59.1$ to 71.9$)$ & $107 \pm 12.1(97.9$ to 115$)$ \\
\hline
\end{tabular}


Table 2 Lipoprotein binding of polyphenols from nuts and lipoproteinbound antioxidant activity

\begin{tabular}{lllc}
\hline & $\begin{array}{l}\text { Phenol } \\
\text { concentration } \\
(\mu \mathrm{M})\end{array}$ & $\begin{array}{l}\text { LDL-bound } \\
\text { polyphenol } \\
\text { concentration } \\
(\mathrm{nmol} / 70 \mu \mathrm{g} \text { protein })\end{array}$ & $\begin{array}{l}\text { Increase } \\
\text { in lag time } \\
v s . \text { control }\end{array}$ \\
Sample & 1 & 0.57 & 5.2 \\
Almond & 5 & 2.64 & 64.8 \\
Almond & 1 & 0.60 & -13.6 \\
Peanut & 5 & 2.50 & 8.2 \\
Peanut & 10 & 5.40 & 48.3 \\
Peanut & 1 & 0.55 & 26.4 \\
Walnut & 5 & 2.37 & 118 \\
Walnut & 5 & & \\
\hline
\end{tabular}

that saturation of protein and nut binding sites has not occurred. This situation allows for valid binding comparisons to be made. With similar amounts of catechin bound for almond, walnut and peanut ( $2.5 \mathrm{nmol})$, the antioxidant effect as measured by the $\%$ increase in lag time $v$. the control was much greater for walnut than the other nuts. Since binding of catechin was similar for the 3 nuts this is an indication that catechin did not interfere with the binding of other nut polyphenols (unidentified). The most accurate method to compare the lipoprotein-bound antioxidant activity is $\mathrm{CLT}_{50}$ which is the concentration to increase the lag time by $50 \% v s$. the control. For almond it is $2.1 \mu \mathrm{M}$, peanut 5.6 $\mu \mathrm{M}$ and walnut $1.0 \mu \mathrm{M}$. Thus walnut-bound polyphenol antioxidants are twice as effective as almond and 5 times those of peanut.

\section{Per capita consumption}

Per capita consumption of nuts was calculated from nut consumption data and the total polyphenol concentration in roasted nuts except for Brazil and Walnut which are eaten raw. Brazil and Cashew consumption were assumed to be equal for our estimate of per capita polyphenol consumption in the USA in 2008/09. Total nut consumption (tree nuts and peanuts) in the USA was estimated at $12.9 \mathrm{~g} \mathrm{day}^{-1}$ which is similar to the 2007 EU consumption of $11.1 \mathrm{~g}_{\text {day }^{-1}}$. Peanuts comprised $65 \%$ of the nut consumption in the US and $45 \%$ in the EU. In the USA the total tree nut polyphenol consumption is an estimated $73.3 \mathrm{mg}$ $\mathrm{day}^{-1}$ and peanuts including peanut butter $88.9 \mathrm{mg} \mathrm{day}^{-1}$ for a total nut contribution in the USA of $162 \mathrm{mg} \mathrm{day}^{-1}$. In the US, almonds were the largest tree nut source of polyphenols very closely followed by walnuts. The greater contribution of polyphenols from peanuts was due to the higher peanut consumption; a total of $7.5 \mathrm{~g} \mathrm{day}^{-1}$ of peanuts vs. $4.4 \mathrm{~g}^{\text {day }}{ }^{-1}$ of tree nuts. Almonds were the most highly consumed tree nut at $1.6 \mathrm{~g} \mathrm{day}^{-1}$ followed by walnuts and pecans at $0.6 \mathrm{~g} \mathrm{day}^{-1}$. In the EU $5.0 \mathrm{~g}$ of peanuts per day were consumed, contributing $71.5 \mathrm{mg}$ of polyphenols. Tree nuts totalled $86.9 \mathrm{mg}$ of polyphenols and thus nut contribution of polyphenols to the EU diet amounted to $158 \mathrm{mg}$ day $^{-1}$, which was very similar to the US diet.

\section{Discussion}

\section{Quantity of antioxidants}

In our assay, which includes raw and roasted nuts, walnuts were superior in antioxidant content to the other nuts. Six other published articles using several different assays and standards measured free polyphenols in raw nuts and four used Folin assays. $^{37-42}$ Walnuts ranked first in 3/4 studies that used Folin and first in the two studies that used a FRAP antioxidant assay. Walnuts were first in both free and total polyphenols in the study that did a hydrolysis. ${ }^{39}$ Raw walnuts, on a serving size basis and using our assay provide the 7th largest amount of total polyphenols among common foods and beverages.

Roasted nuts had $14 \%$ more total polyphenols than raw nuts and the $\%$ free polyphenols decreased. These two results indicate that hydrolysis took place during roasting. This conclusion agrees with studies on almonds and hazelnuts which showed an increase in antioxidant activity following roasting. ${ }^{43,44}$

\section{Antioxidant efficacy}

Our dose-response efficacy assay is equivalent to a comparison of nut polyphenols on a molecule to molecule basis and to other single molecule antioxidants with respect to their ability to react with free radicals. Roasting caused an average decline in efficacy, but the effect was not consistent as seen in Fig. 1. Some nuts decreased in efficacy and others increased during roasting. This is hypothesized to be due to chemical reactions which decrease the concentrations of some polyphenols and increase the concentration of others. This was seen in the aforementioned Hazelnut study in which gallic acid increased and procatechuic acid decreased during roasting. ${ }^{44}$ Walnuts had the highest antioxidant efficacy in our assay indicating their polyphenolic composition was of higher quality than the other nuts. Walnut extract at $1 \mu \mathrm{M}$ (gallic acid equivalents) was previously found to inhibit the oxidation of LDL $84 \% .^{45}$ All nuts had more efficacious antioxidants than $\alpha$-tocopherol. The normal non-supplemented human plasma levels of tocopherol range from 8 to $28 \mu \mathrm{M}$, and average $21 \mu \mathrm{M} .{ }^{46}$ Thus at a possible and reasonable polyphenol plasma concentration of 0.1 to $1 \mu \mathrm{M}$ walnuts may have appreciable plasma antioxidant activity in the presence of tocopherol since walnut's antioxidants have 15 times the efficacy of vitamin E. An in vivo post-prandial LDL antioxidant effect occurred after human consumption of pecans. ${ }^{25}$ Additionally another study showed that post-prandial oxidized LDL significantly decreased with walnut consumption with a high fat meal and endothelial function was also improved. ${ }^{47}$ This antioxidant effect is not due to the change in LDL fat composition since walnuts have the highest PUFA content of all the nuts and PUFA are the most oxidizable fats. Walnuts have the highest content of beneficial linoleic acid and $\alpha$-linolenic acids among the nuts. ${ }^{48}$ Linoleic acid is 3 times higher in walnuts than almonds and almonds have only trace levels of linolenic acid. ${ }^{49}$ These post-prandial results are evidence implicating nut polyphenols or their metabolites as in vivo antioxidants.

There has been few published investigations of absorption and metabolism of nut polyphenols in humans. In a single dose human pecan study unmetabolized epigallocatechin gallate was found in the plasma and reached a maximum of $116 \mathrm{nM}$ at $2 \mathrm{~h}$ post-consumption. ${ }^{25}$ In a comprehensive human study with almond skins monomeric polyphenols were poorly absorbed and appeared as phase II metabolites (glucuronides and sulfates).$^{50} \mathrm{In}$ this study it was found that almond skin polyphenols were $24 \%$ absorbed as measured by Folin polyphenols in the almond and 
Folin levels in urine pre- and post-consumption. Microbialderived conjugated phenolic acid metabolites were the predominant compounds found in plasma and urine and were derived from degradation of monomers and polymeric flavonoids. Over 20 compounds were identified and all of them were conjugated. Our efficacy data in the present study was for aglycones. We have found ferulic acid glucuronide to have better antioxidant efficacy for LDL + VLDL oxidation than the parent compound ferulic acid (Vinson, unpublished results) and this was also the case for LDL oxidation. ${ }^{51} \mathrm{We}$ have also found that ferulic acid glucuronide bound more strongly to LDL + VLDL than ferulic acid (Vinson, unpublished results). Binding to proteins represents one of the non-antioxidant mechanisms for polylphenols in vivo. The health benefits of nuts are not necessarily specifically related to their antioxidant activity. However one study showed a significant positive correlation between nut polyphenol content and cellular antiproliferative activity. ${ }^{39}$

Most recently there has been a supplementation study with mixed nuts ( $50 \%$ walnuts plus almonds and hazelnuts) to subjects with metabolic syndrome. ${ }^{52}$ Metabolomics using LC-MS found that urolithin A (glucuronides and sulfates) and serotonin metabolites were significant biomarkers of nut consumption. Urolithin A is a characteristic microbial-derived metabolite of walnut ellagitannins ${ }^{53}$ and was the most discriminative of the phenolics found in the urine. A thorough search of the literature revealed that only walnuts of the mixed nuts contained ellagitannins. ${ }^{54}$ Walnuts are also considered by the authors to be the source of the serotonin in the urine since walnuts are very high in serotonin..$^{55}$ The same mixed nuts after supplementation to metabolic syndrome subjects produced an improvement in fasting insulin, insulin resistance and inflammatory markers. ${ }^{56}$

\section{Lipoprotein binding}

In our study, walnuts were superior lipoprotein-bound antioxidants to both peanuts and almonds. At similar catechin-bound concentrations for the nuts, walnuts had a 5-fold longer lag time than almonds, and peanuts had a negative effect of lag time $v s$. the control, i.e. pro-oxidant. At $2.6 \mathrm{nmol} / 70 \mu \mathrm{g}$ protein walnut increased the lag time 2-fold compared to almond and 8-fold compared to peanut. Thus at presumably low physiological concentrations (nM to $\mu \mathrm{M}$ ) walnuts would be better in vivo antioxidants than peanut or almond. Catechins have been found in plasma after pecan (human) and almond (hamster) consumption. ${ }^{25,57}$ We have shown previously that a wide variety of pure polyphenols and extracts from foods and beverages bind to LDL + VLDL ${ }^{58}$ Polyphenols from olive oil and red wine have been found bound to LDL after human consumption ${ }^{59,60}$ and thus nut polyphenols could be potent in vivo antioxidants. The binding of nut polyphenols to lipoproteins provides a mechanism for the heart-beneficial decrease in oxidized LDL after nut consumption, specifically for walnuts and almonds. ${ }^{6,47}$

\section{Per capita consumption}

The US per capita consumption of vegetables and fruits has declined $13 \%$ and $6 \%$ since our estimation of polyphenol consumption during the 90's. In 2008 we estimate that $204 \mathrm{mg}$ of polyphenols/day are provided by vegetables and $223 \mathrm{mg} \mathrm{day}^{-1}$ by

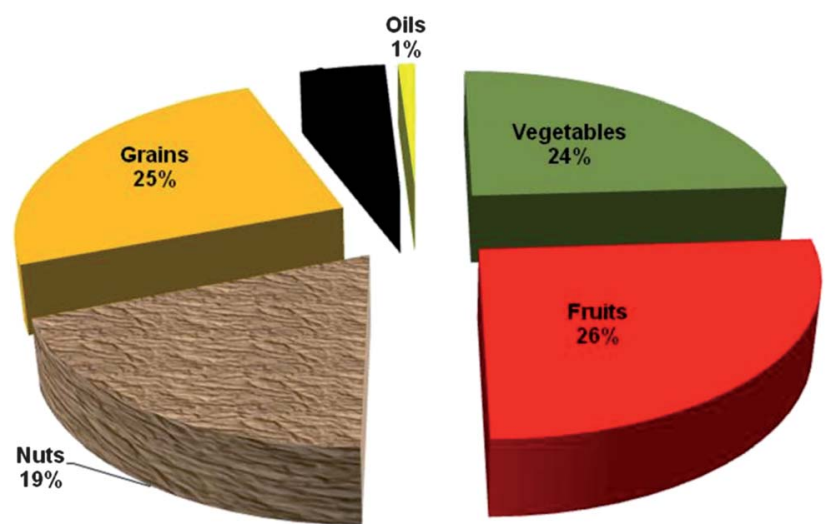

Fig. 2 Daily per capita contribution of polyphenols from food sources to the US diet in 2008 .

fruits. Nuts provide a significant amount of polyphenols, $162 \mathrm{mg}$ day $^{-1}$. We have also analyzed total polyphenols in other foods such as grains, spices and oils and the total polyphenols from all food sources is conservatively estimated as $954 \mathrm{mg} \mathrm{day}^{-1}$ in 2008 . In the USA, nuts provide $19 \%$ of total food polyphenols per day, see Fig. 2. In Spain nuts, including peanuts, provided $12 \%$ of free food polyphenols on a daily basis. ${ }^{61,62} \mathrm{~A}$ single serving (28.4 g) of raw walnuts would provide $575 \mathrm{mg}$ of polyphenols which is greater than the daily sum of these antioxidants provided by fruits and vegetables combined.

\section{Conclusions}

Thus nuts are a major source of antioxidants in the US diet. Nuts are high in fiber, low in saturated fats, high in beneficial unsaturated fats and very high in antioxidants. Nuts are a nutritious snack and food additive providing both nutrients and bioactive antioxidants which provide significant health benefits to the consumer.

\section{References}

1 U.S. Department of Agriculture Nutrient Data Base at http://www. nal.usda.gov/fnic/cgi-bin/nut_search.pl, Accessed January 11, 2011.

2 R. D. Mattes and M. L. Dreher, Nuts and healthy body weight maintenance mechanisms, Asia Pac. J. Clin. Nutr., 2010, 19, 137-141.

3 D. Zambón, J. Sabaté, S. Muñoz, B. Campero, E. Casals, M. Merlos, J. C. Laguna and E. Ros, Substituting walnuts for monounsaturated fat improves the serum lipid profile of hypercholesterolemic men and women. A randomized crossover trial, Ann. Intern. Med, 2000, 132, $538-546$

4 J. Salas-Salvadó, J. Fernández-Ballart, E. Ros, M. A. MartínezGonzález, M. Fitó, R. Estruch, D. Corella, M. Fiol, E. GómezGracia, F. Arós, G. Flores, J. Lapetra, R. Lamuela-Raventós, V. Ruiz-Gutiérrez, M. Bulló, J. Basora and M. I. Covas, Effect of a Mediterranean diet supplemented with nuts on metabolic syndrome status: one-year results of the PREDIMED randomized trial. PREDIMED Study Investigators, Arch. Intern. Med., 2008, 168, 2449-2458.

5 M. Bes-Rastrollo, N. M. Wedick, M. A. Martinez-Gonzalez, T. Y. Li, L. Sampson and F. B. Hu, Prospective study of nut consumption, long-term weight change, and obesity risk in women, Am. J. Clin. Nutr., 2009, 89, 1913-1919.

6 D. J. A. Jenkins, C. W. Kendall, A. Marchie, T. L. Parker, P. W. Connelly, W. Qian, J. S. Haight, D. Faulkner, E. Vidgen, K. G. Lapsley and G. A. Spiller, Dose response of almonds on coronary heart disease risk factors: blood lipids, oxidized lowdensity lipoproteins, lipoprotein(a), homocysteine, and pulmonary 
nitric oxide: a randomized, controlled, crossover trial, Circulation, 2002, 106, 1327-1332.

7 D. J. Jenkins, C. W. Kendall, D. A. Faulkner, T. Nguyen, T. Kemp, A. Marchie, J. M. Wong, R. de Souza, A. Emam, E. Vidgen, E. A. Trautwein, K. G. Lapsley, C. Holmes, R. G. Josse, L. A. Leiter, P. W. Connelly and W. Singer, Assessment of the longer-term effects of a dietary portfolio of cholesterol-lowering foods in hypercholesterolemia, Am. J. Clin. Nutr, 2006, 83, 582-591.

8 S. M. Mercanligil, P. Arslan, C. Alasalvar, E. Okut, E. Akgül, A. Pinar, P. O. Geyik, L. Tokgözoğlu and F. Shahidi, Effects of hazelnut-enriched diet on plasma cholesterol and lipoprotein profiles in hypercholesterolemic adult men, Eur. J. Clin. Nutr, 2007, 61212-61220. Epub 2006

9 S. L. Tey, R. C. Brown, A. W. Chisholm, C. M. Delahunty, A. R. Gray and S. M. Williams, Effects of different forms of hazelnuts on blood lipids and $\alpha$-tocopherol concentrations in mildly hypercholesterolemic individuals, Eur. J. Clin. Nutr., 2011, 65, 117124

10 A. E. Griel, D. D. CaoBagshaw, A. M. Cifelli, B. Holub and P. M. Kris-Etherton, A Macadamia nut-rich diet reduces total and LDL-cholesterol in mildly hypercholesterolemic men and women, $J$. Nutr., 2008, 138, 761-767.

11 S. M. Mercanligil, P. Arslan, C. Alasalvar, E. Okut, E. Akgül, A. Pinar, P. O. Geyik, L. Tokgözoğlu and F. Shahidi, Effects of hazelnut-enriched diet on plasma cholesterol and lipoprotein profiles in hypercholesterolemic adult men, Eur. J. Clin. Nutr., 2007, 61, 212-220

12 N. M. Ghadimi, A. Kimiagar, A. Abadi, M. Mirzazadeh and G. Harrison, Peanut consumption and cardiovascular risk, Public Health Nutr., 2010, 13, 1581-1586. Epub 2009.

13 A. Kocyigit, A. A. Koylu and H. Keles, Effects of pistachio nuts consumption on plasma lipid profile and oxidative status in healthy volunteers, Nutr., Metab. Cardiovasc. Dis., 2006, 16, 202-209.

14 S. K. Gebauer, S. G. West, C. D. Kay, P. Alaupovic, D. Bagshaw and P. M. Kris-Etherton, Effects of pistachios on cardiovascular disease risk factors and potential mechanisms of action: a dose-response study, Am. J. Clin. Nutr, 2008, 88, 651-659.

15 Z. Li., R. Song, C. Nguyen, A. Zerlin, H. Karp, K. Naowamondhol, G. Thames, K. Gao, L. Li, C. H. Tseng, S. M. Henning and D. Heber, Pistachio nuts reduce triglycerides and body weight by comparison to refined carbohydrate snack in obese subjects on a 12-week weight loss program, J. Am. Coll. Nutr, 2010, 29, 198-203.

16 M. Iwamoto, K. Imaizumi, M. Sato, Y. Hirooka, K. Sakai, A. Takeshita and M. Kono, Serum lipid profiles in Japanese women and men during consumption of walnuts, Eur. J. Clin. Nutr., 2002, 56, 629-637.

17 D. Zambón, J. Sabaté, S. Muñoz, B. Campero, E. Casals, M. Merlos, J. C. Laguna and E. Ros, Substituting walnuts for monounsaturated fat improves the serum lipid profile of hypercholesterolemic men and women. A randomized crossover trial, Ann. Intern. Med, 2000, 132 538-546. Erratum in: Ann. Intern. Med. 2000.

18 M. Iwamoto, K. Imaizumi, M. Sato, Y. Hirooka, K. Sakai, A. Takeshita and M. Kono, Serum lipid profiles in Japanese women and men during consumption of walnuts, Eur. J. Clin. Nutr., 2002, 56, 629-637.

19 B. Olmedilla-Alonso, F. Granado-Lorencio, C. Herrero-Barbudo, I. Blanco-Navarro, S. Blázquez-García and B. Pérez-Sacristán, Consumption of restructured meat products with added walnuts has a cholesterol-lowering effect in subjects at high cardiovascular risk: a randomised, crossover, placebo-controlled study, J. Am. Coll. Nutr, 2008, 27, 342-348.

20 R. Estruch, M. A. Martínez-González, D. Corella, J. Salas-Salvadó, V. Ruiz-Gutiérrez, M. I. Covas, M. Fiol, E. Gómez-Gracia, M. C. López-Sabater, E. Vinyoles, F. Arós, M. Conde, C. Lahoz, J. Lapetra, G. Sáez and E. Ros, PREDIMED Study Investigators Effects of a Mediterranean-style diet on cardiovascular risk factors: a randomized trial, Ann. Intern. Med, 2006, 4145, 1-11.

21 P. M. Kris-Etherton, S. Yu-Poth, J. Sabaté, H. E. Ratcliffe, G. Zhao and T. D. Etherton, Nuts and their bioactive constituents: effects on serum lipids and other factors that affect disease risk, Am. J. Clin. Nutr, 1999, 70, 504S-511S.

22 D. J. Jenkins, C. W. Kendall, A. R. Josse, S. Salvatore, F. Brighenti, L. S. Augustin, P. R. Ellis, E. Vidgen and A. V. Rao, Almonds decrease postprandial glycemia, insulinemia, and oxidative damage in healthy individuals, J. Nutr, 2006, 136, 2987-2992.
23 J. Mukuddem-Petersen, W. S. Oosthuizen, J. C. Jerling, S. M. Hanekom and Z. White, Effects of a high walnut and high cashew nut diet on selected markers of the metabolic syndrome: a controlled feeding trial, Br. J. Nutr., 2007, 97, 1144-1153.

24 I. Sari, Y. Baltaci, C. Bagci, V. Davutoglu, O. Erel, H. Celik, O. Ozer, N. Aksoy and M. Aksoy, Effect of pistachio diet on lipid parameters, endothelial function, inflammation, and oxidative status: a prospective study, Nutrition, 2010, 26, 399-404, Epub 2009.

25 C. Hudthagosol, E. H. Haddad, K. McCarthy, P. Wang, K. Oda and J. Sabaté, Pecans acutely increase plasma postprandial antioxidant capacity and catechins and decrease LDL oxidation in humans, $J$. Nutr., 2011, 141, 56-62.

26 M. Fitó, M. Guxens, D. Corella, G. Sáez, R. Estruch, R. de la Torre, F. Francés, C. Cabezas, M. C. López-Sabater, J. Marrugat, A. García-Arellano, F. Arós, V. Ruiz-Gutierrez, E. Ros, J. SalasSalvadó, M. Fiol, R. Solá and M. I. Covas, for the PREDIMED Study Investigators, Effect of a traditional Mediterranean diet on lipoprotein oxidation: a randomized controlled trial, Arch. Intern. Med., 2007, 167, 1195-1203.

27 D. L. McKay, C. Y. Chen, K. J. Yeum, N. R. Matthan, A. H. Lichtenstein and J. B. Blumberg, Chronic and acute effects of walnuts on antioxidant capacity and nutritional status in humans: a randomized, cross-over pilot study, Nutr. J., 2010, 9, 21.

28 P. López-Uriarte, M. Bulló, P. Casas-Agustench, N. Babio and J. Salas-Salvadó, Nuts and oxidation: a systematic review, Nutr. Rev., 2009, 67, 497-508.

29 J. M. Harnly, R. F. Doherty, G. R. Beecher, J. M. Holden, D. B. Haytowitz, S. Bhagwat and S. Gebhardt, Flavonoid content of U.S. fruits, vegetables, and nuts, J. Agric. Food Chem., 2006, 54, 9966-9977.

30 V. L. Singleton, R. Orthofer and R. M. Lamuela-Raventós, Analysis of total phenols and other oxidation substrates by means of FolinCiocalteu reagent, Methods Enzymol., 1999, 299, 152-178.

31 J. A. Vinson, J. Proch and P. Bose, Determination of quantity and quality of polyphenol antioxidants in foods and beverages, Methods Enzymol., 2001, 335, 103-114.

32 J. A. Vinson and B. A. Hontz, Antioxidant Effectiveness of Red and White Wines, J. Agric. Food Chem., 1995, 43, 401-403.

33 Economic Research Service (ERS), U.S. Department of Agriculture (USDA). Food Availability (Per Capita) Data System. http://www. ers.usda.gov/Data/FoodConsumption, Accessed January 11, 2011.

34 J. A. Vinson, X. Su, L. Zubik and P. Bose, Phenol antioxidant quantity and quality in foods: fruits, J. Agric. Food Chem., 2001, 49, 5315-5321.

35 J. A. Vinson, Y. Hao, X. Su and L. S. Zubik, Phenol antioxidant quantity and quality in foods: vegetables, J. Agric. Food Chem., 1998, 46, 3630-3634.

36 CBI Market Survey: The Edible Nuts and Dried Fruit and Vegetables Market in the EU, Centre for the Promotion of imports from developing countries, Rotterdam, The Netherlands, 2009.

37 M. Kornsteiner, K.-H. Wagner and I. Elmadfa, Tocopherols and total phenolics in 10 different nut types, Food Chem., 2006, 98, 381387.

38 N. Pellegrini, M. Serafini, S. Salvatore, D. Del Rio, M. Bianchi and F. Brighenti, Total antioxidant capacity of spices, dried fruits, nuts, pulses, cereals and sweets consumed in Italy assessed by three different in vitro assays, Mol. Nutr. Food Res., 2006, 50, 10301038.

39 J. Yang, R. H. Liu and L. Halim, Antioxidant and antiproliferative activities of common edible nut seeds, LWT-Food Sci. Technol., $2009,42,1-8$

40 X. Wu, G. R. Beecher, J. M. Holden, D. B. Haytowitz, S. E. Gebhardt and R. L. Prior, Lipophilic and hydrophilic antioxidant capacities of common foods in the United States, J. Agric. Food Chem., 2004, 52, 4026-4037.

41 R. Blomhoff, M. H. Carlsen, L. F. Andersen and D. R. Jacobs Jr, Health benefits of nuts: potential role of antioxidants, Br. J. Nutr., 2006, 96(Suppl. 2), S52-60.

42 B. J. Macfarlane, W. R. Bezwoda, T. H. Bothwell, R. D. Baynes, J. E. Bothwell, A. P. MacPhail, R. D. Lamparelli and F. Mayet, Inhibitory effect of nuts on iron absorption, Am. J. Clin. Nutr, 1988, 47, 270-274.

43 I. Garrido, M. Monagas, C. Gómez-Cordovés and B. J. Bartolomé, Polyphenols and antioxidant properties of almond skins: influence of industrial processing, J. Food Sci., 2008, 73, C106-115. 
44 V. Schmitzer, A. Slatnar, R. Veberic, F. Stampar and A. Solar, Roasting Affects Phenolic Composition and Antioxidative Activity of Hazelnuts (Corylus avellana L.), J. Food Sci., 2011, 76, S14-19.

45 K. J. Anderson, S. S. Teuber, A. Gobeille, P. Cremin, A. L. Waterhouse and F. M. Steinberg, Walnut polyphenolics inhibit in vitro human plasma and LDL oxidation, J. Nutr, 2001, 131, 2837-2842.

46 A. C. Chang, Normal plasma vitamin E concentration, Biochem. J, 1989, 260, 623.

47 B. Cortés, I. Núñez, M. Cofán, R. Gilabert, A. Pérez-Heras, E. Casals, R. Deulofeu and E. Ros, Acute effects of high-fat meals enriched with Walnuts or olive oil on postprandial endothelial function, J. Am. Coll. Cardiol., 2006, 48, 1666-1671.

48 E. Ros and J. Mataix, Fatty acid composition of nuts-implications for cardiovascular health, Br. J. Nutr., 2006, 96(Suppl. 2), S29-35.

49 S. K. Sathe, N. P. Seeram, H. H. Kshirsagar, D. Heber and K. A. Lapsley, Fatty acid composition of California grown almonds, J. Food Sci., 2008, 773, C607-614.

50 M. Urpi-Sarda, I. Garrido, M. Monagas, C. Gómez-Cordovés, A. Medina-Remón, C. Andres-Lacueva and B. Bartolomé, Profile of plasma and urine metabolites after the intake of almond [Prunus dulcis (Mill.) D.A. Webb] polyphenols in humans, J. Agric. Food Chem., 2009, 57, 10134-42.

51 T. Ohta, T. Nakano, Y. Egashira and H. Sanada, Antioxidant activity of ferulic acid beta-glucuronide in the LDL oxidation system, Biosci., Biotechnol., Biochem., 1997, 61, 1942-3.

52 S. Tulipani, R. Llorach, O. Jáuregui, P. López-Uriarte, M. GarciaAloy, M. Bullo, J. Salas-Salvadó and C. Andrés-Lacuaeva, Metabolomics unveils urinary change in subjects with metabolic Syndrome, J. Proteome Res., 2011, 10, 5047-8.

53 B. Cerdá, F. A. Tomás-Barberán and J. C. Espín, Metabolism of antioxidant and chemopreventive ellagitannins from strawberries, walnuts, and oak-aged wine in humans: identification of biomarkers and individual variability, J. Agric. Food Chem., 2005, 53, 227-35.

54 L. Tieme, F. M. Lajola and M. I. Genovese, Comparison of polyphenol content and antioxidant capacity of nuts, Cienc. Tecnol. Aliment., 2010, 30, 254-9.
55 L. Kema, A. Schellings, G. Meiborg, C. Hoppenbrouwers and F. Muskiet, Influence of a serotonin- and dopamine-rich diet on platelet serotonin content and urinary excretion of biogenic amines and their metabolites, Clin. Chem, 1992, 38, 1730-6.

56 F. Casas-Agustench, F. López-Uriarte, M. Bulló, E. Ros, J. J. CabréVilla and J. Salas-Salvadó, Effects of one serving of mixed nuts on serum lipids, insulin resistance and inflammatory markers in patients with metabolic syndrome, Nutr., Metab. Cardiovasc. Dis., 2011, 21, 126-35.

57 C. Y. Chen, P. E. Milbury, K. Lapsley and J. B. Blumberg, Flavonoids from almond skins are bioavailable and act synergistically with vitamins $\mathrm{C}$ and $\mathrm{E}$ to enhance hamster and human LDL resistance to oxidation, J. Nutr, 2005, 135, 13661373.

58 J. A. Vinson, J. Jang, Y. A. Dabbagh, M. S. Serry and S. Cai, Plant polyphenols exhibit lipoprotein-bound antioxidant activity using an in vitro oxidation model for heart disease, J. Agric. Food Chem., 1995, 43, 2798-2799.

59 M. I. Covas, K. de la Torre, M. Farré-Albaladejo, J. Kaikkonen, M. Fitó, C. López-Sabater, M. A. Pujadas-Bastardes, J. Joglar, T. Weinbrenner, R. M. Lamuela-Raventós and R. de la Torre, Postprandial LDL phenolic content and LDL oxidation are modulated by olive oil phenolic compounds in humans, Free Radical Biol. Med., 2006, 40, 608-616.

60 M. Urpí-Sardà, O. Jáuregui, R. M. Lamuela-Raventós, W. Jaeger, M. Miksits, M. I. Covas and C. Andres-Lacueva, Uptake of diet resveratrol into the human low-density lipoprotein. Identification and quantification of resveratrol metabolites by liquid chromatography coupled with tandem mass spectrometry, Anal. Chem., 2005, 77, 3149-3155.

61 M. I. Covas, K. de la Torre, M. Farré-Albaladejo, J. Kaikkonen, M. Fitó, C. López-Sabater, M. A. Pujadas-Bastardes, J. Joglar, T. Weinbrenner, R. M. Lamuela-Raventós and R. de la Torre, Nut consumption in Spain and other countries, Br. J. Nutr, 2006, 96 (Suppl. 2), S-3-11.

62 F. Saura-Calixto and I. Goni, Antioxidant capacity of the Spanish Mediterranean diet, Food Chem., 2006, 94, 442-47. 